CLINICAL STUDY

\title{
Surgery for 'asymptomatic' mild primary hyperparathyroidism improves some clinical symptoms postoperatively
}

\author{
Claire Blanchard, Muriel Mathonnet ${ }^{1}$, Frédéric Sebag ${ }^{2}$, Cécile Caillard, Antoine Hamy ${ }^{3}$, Christelle Volteau ${ }^{4}$, \\ Marie-Françoise Heymann ${ }^{5}$, Vincent Wyart, Delphine Drui ${ }^{6}$, Malanie Roy, Bertrand Cariou ${ }^{6}$, \\ Françoise Archambeaud ${ }^{7}$, Patrice Rodien ${ }^{8}$, Jean-François Henry ${ }^{2}$, Rasa Zarnegar ${ }^{9}$, Jean-Benoît Hardouin ${ }^{4,10}$ \\ and Eric Mirallié \\ Clinique de Chirurgie Digestive et Endocrinienne (CCDE), Institut des Maladies de l'Appareil Digestive (IMAD), Centre Hospitalier Universitaire (CHU) \\ Nantes-Hôtel Dieu, Place Alexis Ricordeau, 44093 Nantes, France, ${ }^{1}$ Service de Chirurgie Digestive, Hôpital Dupuytren, 87042 , Limoges, France, ${ }^{2}$ Service \\ de Chirurgie Générale et Endocrinienne, Hôpital de la Timone, 13385 Marseille Cedex, France, ${ }^{3}$ Service de Chirurgie Digestive, CHU Angers, 49933 \\ Angers Cedex 9, France, ${ }^{4}$ Plateforme de Biométrie, CHU Nantes, 44093 Nantes, France, ${ }^{5}$ Service d'Anatomie Pathologique, CHU Nantes, 44093 Nantes, \\ France, ${ }^{6}$ Service d'Endocrinologie, CHU Nantes, 44093 Nantes, France, ${ }^{7}$ Service de Médecine Interne, Endocrinologie et Maladies Métaboliques, CHU \\ Limoges, Limoges, France, ${ }^{8}$ Service d'Endocrinologie, CHU d'Angers, 49000 Angers, France, ${ }^{9}$ Department of Surgery, Weill Cornell Medical College, \\ New-York Presbyterian Hospital, New York, New York, USA and ${ }^{10}$ EA 4275-SPHERE, Faculté de Médecine et Pharmacie, 44035 Nantes Cedex 1, France \\ (Correspondence should be addressed to E Mirallié; Email: eric.mirallie@chu-nantes.fr)
}

\begin{abstract}
Objective and background: Most primary hyperparathyroidism (pHPT) patients do not conform to the guidelines for parathyroidectomy established by an international panel of specialists and have a mild pHPT. This group is typically defined as 'asymptomatic'. The primary aim of this study was to determine symptom improvement in this 'asymptomatic' group after parathyroidectomy. Secondly, we aimed to create a preoperative clinical score predicting postoperative symptom resolution.

Design: A prospective nonrandomized study included patients with mild pHPT.

Methods: A questionnaire (22 items) was given to 'asymptomatic' patients preoperatively and at 3, 6, and 12 postoperative months. A logistic regression was performed to create a preoperative clinical score. Results: One hundred and sixteen patients were included. Postoperatively, HPT was resolved in $98 \%$ of patients. Twelve of 22 nonspecific symptoms were improved at 1 year. Subgroups analysis showed a greater improvement in patients $<70$ years and those with a serum calcium level $\geq 2.6 \mathrm{mmol} / \mathrm{l}$ preoperatively. A clinical score, based on age and five symptoms, was established to predict the clinical improvement after surgery in mild pHPT patients with a positive predictive value of $81 \%$.

Conclusion: Patients with asymptomatic pHPT have clinical improvement of their symptoms postoperatively even after 1 year. Younger patients and those with higher preoperative calcium levels show the best improvement.
\end{abstract}

European Journal of Endocrinology 169 665-672

\section{Introduction}

Primary hyperparathyroidism (pHPT) is due to an inappropriate secretion of parathyroid hormone (PTH) by one or more pathological parathyroid glands, which causes hypercalcemia associated with hypercalciuria and hypophosphatemia. Currently, most pHPT patients (80\% of cases) present with mild pHPT, defined by moderate hypercalcemia $(\leq 2.85 \mathrm{mmol} / \mathrm{l})$ and a $24-\mathrm{h}$ urine calcium level $\leq 10 \mathrm{mmol}$. Most patients with mild pHPT are considered to be asymptomatic $(1,2)$. Following the consensus statement of an international workshop, guidelines have been established concerning indication for surgery (3, 4, 5). Indication for parathyroidectomy comprises the following criteria: serum calcium level $\geq 2.85 \mathrm{mmol} / \mathrm{l}$, calciuria $>10 \mathrm{mmol} / 24 \mathrm{~h}$, creatinine clearance decreased by $\geq 10 \%$ of normal level, bone mineral density (BMD) reduced by $>2.5 \mathrm{~T}$-score, and age $\leq 50$ years. Patients who do not meet these criteria can either undergo surgery or be managed medically $(6,7)$.

Over the last few years, knowledge about mild pHPT has dramatically increased. Some studies have shown the benefit of surgery for patients with mild pHPT. Our group conducted a prospective, multicentric study, in patients with pHPT, evaluating some nonspecific symptoms and quality of life criteria using the SF-36v2 (8). The results showed that the surgical cure of pHPT significantly improved the quality of life and decreased the number of nonspecific symptoms (appetite loss, thirst, headache, and nausea) 1 year after surgical cure. Other studies drew the same conclusions and a French consensus suggested surgery for all patients with pHPT (9). Randomized studies often showed a 
moderate improvement of quality of life in operated patients, but none have evaluated nonspecific symptoms $(10,11)$. Surgery is followed by the normalization of calcium and PTH levels, a decrease in bone turnover, and an increase in BMD in lumber spine and femoral neck $(7,10,11)$.

Patients with mild pHPT often have nonspecific symptoms: fatigue, mood disorders, anxiety, depression, irritability, headache, constipation, and abdominal pain, among others $(12,13)$. These symptoms are never cited in the consensus conferences and therefore are not used as indications for surgery in mild pHPT patients. Consequently, subjective symptoms and their presumable effects on patients' quality of life are not indications for parathyroidectomy.

The question remains unanswered whether all patients with mild pHPT should undergo surgery and which clinical symptoms should be taken into account before surgery. The purposes of this study were i) to evaluate nonspecific symptoms in patients with mild pHPT preoperatively and 3, 6, and 12 months postoperatively and ii) to create a new preoperative clinical score to predict clinical improvement after surgery.

\section{Subjects and methods}

Between December 2007 and June 2010, patients from four French Departments of Endocrine Surgery, Hospitals of Angers, Limoges, Marseille, and Nantes, were prospectively enrolled in a multicentric study. Departments of Endocrine Surgery of Marseille and Angers only included patients between October 2009 and June 2010. During this period, all patients with mild pHPT scheduled for parathyroidectomy were evaluated for inclusion. Inclusion criteria included calcium level between 2.6 and $2.85 \mathrm{mmol} / \mathrm{l}$ (normal: $2.3-2.6 \mathrm{mmol} / \mathrm{l}$ ) with a PTH level $\geq 25 \mathrm{ng} / \mathrm{l}$ and a serum creatinine level $<160 \mu \mathrm{mol} / \mathrm{l}$, or a serum calcium level between 2.5 and $2.6 \mathrm{mmol} / \mathrm{l}$ and a PTH level $\geq 35 \mathrm{ng} / \mathrm{l}$. To measure calcemia, blood samples were collected and centrifuged at $2000 \boldsymbol{g}$ for $10 \mathrm{~min}$ at $4{ }^{\circ} \mathrm{C}$ within $1 \mathrm{~h}$ after venipuncture. Total calcium on heparinized plasma was determined using the method according to Schwarzenbach with o-cresolphthalein complexone on cobas c6000 Roche system with intraassay coefficients of variation below or equal to $0.7 \%$. Calcemia was not albumin-corrected, because the total calcium is used in clinical practice. In addition, the difference between the total calcium and corrected calcium is not major, concerning the healthy subjects.

Exclusion criteria included all patients with pHPT who met NIH criteria for parathyroidectomy (calcium level $>2.85 \mathrm{mmol} / \mathrm{l}$, calciuria $>10 \mathrm{mmol} / 24 \mathrm{~h}$, creatinine clearance decreased by $>10 \%$, and age $<50$ years). Other exclusion criteria include benign familial hypocalciuric hypercalcemia, multiple endocrine neoplasia, serum creatinine level $>160 \mu \mathrm{mol} / \mathrm{l}$ (to exclude patients with secondary HPT), and patients under medication containing lithium or thiazide diuretics, as well as comorbidities which could be responsible for some evaluated symptoms. Patients could not participate in another study over a period of 1 year after inclusion. The study was approved by the Institutional Local Review Board Committee (University Hospital of Angers, France. \#2012/45).

Biological cure was defined by a normal serum calcium level 3 months after surgery. All patients were asked to fill in a questionnaire about nonspecific symptoms preoperatively and 3, 6, and 12 months postoperatively. The questionnaire of nonspecific symptoms was created using previously published data $(8,13,14,15)$. This questionnaire evaluated the presence and severity of 22 symptoms frequently observed in patients with pHPT (Table 1). Demographic, clinical, and biological data (serum calcium, PTH, $25-\mathrm{OH}$ vitamin $\mathrm{D}$, and creatinine levels) were collected prospectively during the preoperative period, and 3, 6 , and 12 months after parathyroidectomy. The normal range of PTH level was 25-65 ng/l. Vitamin D was normal when above $35 \mathrm{ng} / \mathrm{l}$. The types of anesthesia (local or general) and cervical approach (bilateral, unilateral, or videoscopic) were left to surgeons' discretion.

All patients received a written explanation of the study protocol and gave their signed, informed consent. The morbidity (hypoparathyroidism, recurrent nerve palsy, and postoperative hematoma) and the operative mortality were specified.

\section{Statistical analysis}

Median values of biological markers were compared between a baseline and each of the follow-up visits

Table 1 Twenty-two nonspecific symptoms.

\begin{tabular}{ll}
\hline No. & 22 Nonspecific symptoms \\
\hline 1 & Appetite loss \\
2 & Weight loss \\
3 & Thirst \\
4 & Polyuria \\
5 & Headaches \\
6 & Itchy skin \\
7 & Bone pain \\
8 & Joint pain \\
9 & Muscular pain \\
10 & Muscular weakness \\
11 & Mobility difficulties \\
12 & Nausea \\
13 & Abdominal pain \\
14 & Abdominal distension \\
15 & Constipation \\
16 & Ulcer \\
17 & Fatigue \\
18 & Depression \\
19 & Mood swings \\
20 & Irritability \\
21 & Anxiety \\
22 & Forgetfulness \\
\hline
\end{tabular}


(3, 6, and 12 months) using Wilcoxon's signed-rank test. The prevalence of each nonspecific symptom was compared between a baseline and each of the follow-up visit using McNemar's test.

A score of prediction of clinical improvement was then established using a logistic regression. Clinical improvement was evaluated by using questions addressing the subjective improvement of overall health at the 1-year visit. We divided the study population into two groups: i) patients who did not feel better (felt the same or worse compared with before surgery) 1 year after surgery in terms of their perception of their overall health; and ii) patients who felt better 1 year after surgery in terms of their perception of their overall health.

In order to build a score predicting the postoperative belonging to one of these two groups, we introduced in the logistic regression the presence or absence at baseline of nonspecific symptoms, age of the patients $(<70$ vs $\geq 70$ years $)$, calcium level $(<2.6 \mathrm{vs} \geq 2.6 \mathrm{mmol} / \mathrm{l})$, and vitamin D levels $(<\mathrm{vs}$ $\geq 35 \mathrm{ng} / \mathrm{l})$. Variables were selected using a stepby-step backward selection procedure with type-I error established at $10 \%$ in order to keep in the score variables that could be at the limit of the significance (between 5 and 10\%), but that was important to improve the predictive properties of the score. This analysis highlighted the most relevant preoperative symptoms to predict the improvement of health after surgical cure of mild pHPT. Visual inspection of the Receiver Operating Characteristic (ROC) curve associated with this logistic regression enabled determination of a threshold value on the obtained score in order to divide the patients into two groups (improvement and nonimprovement) so as to achieve the lowest possible rate of misclassified patients. To choose the value, the specificity of the score was favored in order to detect a maximal number of patients presenting an improvement of their overall vision health. The score obtained by the logistic regression was composed of decimal weights associated with each retained variable. In order to create a simpler score, for an easy use in a clinical context, these weights have been proportionally transformed in obtain weights among the first integers $(1,2$, or 3$)$.

\section{Results}

\section{Preoperative data}

One hundred and sixteen patients were enrolled in this study. Median age was 68 years old (range 51-87). There were 90 females $(78 \%)$ and 26 males $(22 \%)$. Median preoperative serum calcium value was $2.67 \mathrm{mmol} / \mathrm{l}$ (range 2.50-2.85) and median PTH level was $92 \mathrm{pg} / \mathrm{l}$ (range 38-310) (Table 2). Ninety patients (78\%) had a vitamin D deficiency and 13 (11\%) had normal vitamin D level (missing data in 25 patients). Twenty-nine patients (33\%) had a normal serum calcium level $(\leq 2.6 \mathrm{mmol} / \mathrm{l})$ associated with increased PTH concentration.

Preoperatively, the most commonly reported nonspecific symptoms included the following: fatigue (53\%), anxiety (50\%) and bone pain (44\%) (Table 3).

\section{Surgery and pathology}

The types of surgical procedure were classic Kocher $(78 \%)$, lateral cervicotomy $(17 \%)$, or focal approach using cervicoscopy (5\%). A total of 94 (81\%) parathyroidectomies were performed under general anesthesia and $22(19 \%)$ under local anesthesia (five under hypnosis). There was no perioperative mortality, and postoperative morbidity was 3\%: one patient developed a superficial hematoma that required reoperation and three patients had transitory recurrent laryngeal nerve palsy. There was no postoperative (transient or permanent) hypocalcemia (defined by calcium level below $2.00 \mathrm{mmol} / \mathrm{l})$.

Histologic examination revealed 107 solitary adenomas $(92 \%)$ and nine cases of multiglandular disease (hyperplasia or multiple adenomas) (8\%). There was no parathyroid carcinoma.

\section{Evolution of biology after surgery}

Three months after surgery The median serum calcium level was normalized after surgery and remained normal at 3 months. Median serum calcium and PTH levels are indicated in Table 2. Calcium and PTH levels normalized in 96 patients (83\%). High

Table 2 Significant decrease over time of biological data (median (min-max)).

\begin{tabular}{|c|c|c|c|c|}
\hline & Preoperative (\%) & 3 months & 6 months & 1 year \\
\hline Calcemia (median (min-max)) (mmol/l) & $2.67(2.50-2.85)$ & $2.40 *(1.93-2.75)$ & $2.37^{*}(2.05-2.72)$ & $2.37^{*}(2.00-2.95)$ \\
\hline $\begin{array}{l}\text { Phosphoremia (median (min-max)) } \\
\quad(\mathrm{mmol} / \mathrm{l})\end{array}$ & $0.82(0.34-2.87)$ & $1.10 *(0.64-1.67)$ & $1.07^{*}(0.51-1.57)$ & $1.14^{\star}(0.64-1.71)$ \\
\hline PTH (median (min-max)) (pg/l) & $92.70(38.10-310.00)$ & $34.30 *(0.90-278.00)$ & $48.50 *(27.00-102.10)$ & $44.00 *(0.50-164.00)$ \\
\hline Creatinine (median (min-max)) $(\mu \mathrm{mol} / \mathrm{l})$ & $69.00(35.00-125.00)$ & NA & NA & 83.65 (70.00-97.30) \\
\hline $\begin{array}{l}25 \text { OH-hydroxyvitamin D } \\
\text { (median (min-max)) ( } \mu \mathrm{g} / \mathrm{l})\end{array}$ & $18.80(2.46-73.60)$ & $27.05^{\star}(6.82-80.00)$ & NA & $25.20 *(8.00-74.00)$ \\
\hline
\end{tabular}

${ }^{\star} P<0.05$ (statistical data relative to preoperative). 
PTH levels $(>60 \mathrm{pg} / \mathrm{l})$ with normocalcemia were observed in 16 patients $(13 \%)$. Three patients had a persistent hypercalcemia at 3 months with normal PTH levels (3\%). The median serum phosphorus level was also normalized at 3 months $(>0.8 \mathrm{mmol} / \mathrm{l})$. Sixty-three $(54 \%)$ patients had persistent vitamin D deficiency albeit they all had postoperative vitamin $\mathrm{D}$ supplementation.

Six months after surgery Median serum calcium and PTH levels are indicated in Table 2. The median serum calcium level and PTH levels were normalized at 6 months. Only five patients had hypercalcemia.

Twelve months after surgery Median serum calcium and PTH levels are indicated in Table 2. Only five patients had hypercalcemia. Among the 16 patients with high PTH level and normocalcemia at 3 months, two still had an elevated PTH level with normocalcemia 12 months postoperatively. These were considered as persistent hypercalcemia (HPT). These patients had a median preoperative PTH level above the median of the preoperative overall analysis $(127 \mathrm{vs} 92.70 \mathrm{pg} / \mathrm{l})$. The median serum phosphorus level was normalized at 1 year. Concerning the vitamin D, 37 patients $(32 \%)$ were considered as vitamin D replete, $33(28 \%)$ as vitamin D deplete, and data were missing for 46 (40\%).

\section{Evolution of nonspecific symptoms}

Three months after surgery At 3 months, $97 \%$ of questionnaires were completed. Nineteen out of 22 nonspecific symptoms decreased after surgery (Table 3).
This decrease was statistically significant for 12 items: appetite loss, weight loss, thirst, polyuria, bone pain, muscular weakness, nausea, constipation, fatigue, depression, mood swings, and anxiety.

Six months after surgery At 6 months $(88 \%$ of questionnaires completed), only six symptoms were significantly improved (appetite loss, thirst, bone pain, constipation, fatigue, and mood swings).

Twelve months after surgery At 1 year $(89 \%$ of questionnaires completed), 15 of the 22 symptoms decreased and 11 symptoms were significantly improved (appetite loss, weight loss, thirst, polyuria, bone pain, constipation, fatigue, depression, mood swings, irritability, and anxiety). The level of vitamin D did not influence the nonspecific symptoms improvement.

\section{Nonspecific symptoms according to age ( $<70$ or $\geq 70$ years)}

Patients were classified according to an age cut-off ( $<70$ or $\geq 70$ years). It was the most relevant cut-off of improvement based on age. Sixty-seven patients were under 70 years before surgery and 49 patients were older. Preoperatively, there was no significant difference between the two age groups concerning nonspecific symptoms. At 1 year, all biological parameters were significantly improved regardless of the patients' age. Improvement of nonspecific symptoms at 1 year was greater in patients $<70$ years in whom nine symptoms significantly improved, while only four symptoms significantly improved in patients $\geq 70$ years (Table 4 ).

Table 3 Nonspecific symptoms in all patients at preoperative period, 3, 6, and 12 months.

\begin{tabular}{|c|c|c|c|c|}
\hline Symptoms & Preoperative (\%) & 3 months (\%) & 6 months (\%) & 12 months (\%) \\
\hline Appetite loss & 22 & $6^{*}$ & $11^{*}$ & $6^{*}$ \\
\hline Weight loss & 24 & $11^{*}$ & 15 & $13^{*}$ \\
\hline Thirst & 29 & $12^{*}$ & $8^{*}$ & $5^{\star}$ \\
\hline Polyuria & 26 & $18^{*}$ & 15 & $12^{*}$ \\
\hline Headaches & 22 & 14 & 13 & 14 \\
\hline Itchy skin & 13 & 10 & 15 & 13 \\
\hline Bone pain & 44 & $28^{*}$ & $27^{*}$ & $33^{*}$ \\
\hline Joint pain & 38 & 38 & 36 & 39 \\
\hline Muscular pain & 25 & 20 & 25 & 25 \\
\hline Muscular weakness & 37 & $27^{\star}$ & 26 & 23 \\
\hline Mobility difficulties & 18 & 17 & 16 & 16 \\
\hline Nausea & 8 & $2^{*}$ & 6 & 5 \\
\hline Abdominal pain & 15 & 17 & 18 & 15 \\
\hline Abdominal distension & 37 & 33 & 36 & 35 \\
\hline Constipation & 28 & $17^{\star}$ & $15^{\star}$ & $17^{\star}$ \\
\hline Ulcer & 12 & 15 & 15 & 14 \\
\hline Fatigue & 53 & $31^{*}$ & $32^{*}$ & $28^{*}$ \\
\hline Depression & 27 & $18^{*}$ & 15 & $14^{*}$ \\
\hline Mood swings & 27 & $17^{*}$ & $15^{\star}$ & $16^{*}$ \\
\hline Irritability & 27 & 21 & 24 & $18^{*}$ \\
\hline Anxiety & 50 & $34^{*}$ & 44 & $34^{*}$ \\
\hline Forgetfulness & 25 & 21 & 28 & 25 \\
\hline
\end{tabular}

${ }^{\star} P<0.05$ (statistical data relative to preoperative). 
Table 4 Nonspecific symptoms significantly improved at 1 year according to age ( $<70$ or $\geq 70$ years).

\section{Nonspecific symptoms significantly improved at 1 year}

\begin{tabular}{ll}
\hline$<70$ years & $\geq 70$ years \\
\hline Appetite loss & Appetite loss \\
Thirst & Thirst \\
Headaches & Headaches \\
Bone pain & Fatigue \\
Muscular weakness & \\
Constipation & \\
Fatigue & \\
Mood swings & \\
Anxiety & \\
\hline
\end{tabular}

\section{Nonspecific symptoms according to serum calcium level $(<2.6$ or $\geq 2.6 \mathrm{mmol} / \mathrm{l})$}

We classified patients using calcemia cut-off criteria $(<2.6$ or $\geq 2.6 \mathrm{mmol} / \mathrm{l})$. This cut-off was used because it was the upper normal limit. Twenty-nine patients had serum calcium levels $<2.6 \mathrm{mmol} / \mathrm{l}$ before surgery and 87 patients had serum calcium levels $\geq 2.6 \mathrm{mmol} / \mathrm{l}$. At 1 year, calcium, phosphorus, and PTH levels were significantly improved in all patients. Preoperatively, there was a significant difference in the prevalence of thirst and constipation, 7 and $13 \%$ in patients with calcium level $<2.6 \mathrm{mmol} / \mathrm{l}$ vs 30 and $32 \%$ for patients with calcium level $\geq 2.6 \mathrm{mmol} / \mathrm{l}$ respectively. Improvement of nonspecific symptoms at 1 year was better in patients with serum calcium levels $\geq 2.6 \mathrm{mmol} / \mathrm{l}$. Indeed, at 1 year, for these patients 12 symptoms remained significantly improved (Table 5), whereas in patients with serum calcium levels $<2.6 \mathrm{mmol} / \mathrm{l}$, two symptoms remained significantly improved (Table 5).

\section{Preoperative clinical score}

The purpose of the preoperative score was to detect the patients who will be clinically benefited from the surgery. A logistic regression enabled to create a score describing clinical improvement at 1 year as a function of age $(P=0.03)$, and five nonspecific symptoms (weight loss $(P=0.01)$, abdominal pain $(P=0.03)$, abdominal distension $(P=0.06)$, fatigue $(P=0.002)$, and depressive symptoms $(P=0.03))$. The vitamin $D$ level had no influence on the score preoperatively $(P=0.74)$ and at 1 year $(P=0.27)$. The parameters obtained from the logistic regression were then standardized to obtain a score between 0 and 12 (Table 6). The higher the score correlated with greatest improvement.

A cut-off at 3 allowed a specificity of $91 \%$ and sensitivity of $54 \%$ to be obtained for failure of improvement. The positive predictive value (PPV) was $81 \%$ and negative predictive value was $72 \%$.
Patients with a high predictive score should be advised that they have a greater probability of symptom improvement compared with patients with a score $\leq 3$.

\section{Discussion}

The aim of the study was to describe the numerous nonspecific symptoms correlated with mild pHPT, and to evaluate the evolution of these symptoms 3, 6, and 12 months after parathyroidectomy. This study also provided a preoperative score to detect patients who would most improve symptomatically postoperatively.

Many investigators currently agree that most patients with mild pHPT have a constellation of nonspecific symptoms that are not considered as the 'classic' symptoms of pHPT. Whether parathyroidectomy is beneficial in patients without classic symptoms remains a controversial issue. The questionnaire of nonspecific symptoms was based on literature reviews $(8,12,16)$. The present series confirm that weight loss, fatigue, anxiety, and bone pain were the most frequent symptoms in patients with mild pHPT. Other authors have described the high prevalence of these symptoms. Joborn et al. had already used a psychiatric score, the Hopkins symptom checklist, to compare a group of control patients with a group of pHPT patients. They demonstrated that some psychiatric symptoms had a higher incidence in the pHPT group than in the control group (12). The most frequent symptoms were anxiety, depression, and cognitive impairment. Siperstein et al. (13) published a study on 42 patients with pHPT, in which fatigue, muscle weakness, high blood pressure, and bone and joint pain were frequently observed preoperatively regardless of the preoperative serum calcium levels. Roman et al. (17) showed that reduction in mood swings and anxiety symptoms were associated with reduction of PTH level in patients with pHPT who underwent successful parathyroidectomy. Weber et al. (18) confirmed that depression, anxiety, and impaired quality of life were related to pHPT. In their

Table 5 Nonspecific symptoms significantly improved at 1 year according to serum calcium level ( $<2.6$ or $\geq 2.6 \mathrm{mmol} / \mathrm{l})$.

\begin{tabular}{ll}
\hline \multicolumn{2}{c}{ Nonspecific symptoms significantly improved at $\mathbf{1}$ year } \\
\hline$\geq 2.6 \mathrm{mmol} / \mathrm{l}$ & $<2.6 \mathrm{mmol} / \mathrm{I}$ \\
\hline Appetite loss & Thirst \\
Thirst & Fatigue \\
Polyuria & \\
Headaches & \\
Bone pain & \\
Constipation & \\
Fatigue & \\
Depression & \\
Mood swings & \\
Irritability & \\
Anxiety & \\
\hline
\end{tabular}


Table 6 Calculation of the preoperative clinical score.

\begin{tabular}{llc}
\hline Variable & Response & Points \\
\hline Age & $\geq 70$ years & 0 \\
& $<70$ years & 1 \\
Weight loss & No & 0 \\
& Yes & 2 \\
Abdominal pain & Never or sometimes & 0 \\
\multirow{2}{*}{ Abdominal distension } & Often or always & 3 \\
\multirow{2}{*}{ Fatigue } & Often or always & 0 \\
\multirow{2}{*}{ Depressive symptoms } & Never or sometimes & 1 \\
\multirow{2}{*}{ Score (sum) } & Never or sometimes & 0 \\
& Often or always & 3 \\
& Often or always & 2 \\
& Never or sometimes & 0 \\
& & 12 \\
\hline
\end{tabular}

series, successful parathyroidectomy reduced psychopathologic symptoms.

Similarly to prior studies, this study has shown that patients with mild pHPT had nonspecific symptoms that remained significantly improved 1 year after surgery. There was a weak significance $(P<0.05)$ for all improved symptoms. This is not surprising because all patients included were affected with asymptomatic HPT. There was a difference between 3 months (12 items improved), 6 months (six items), and 12 months (11 items) after surgery. At 3 months, patients can have a placebo effect of surgery. With time, effects of surgery appear. This could be an explanation for the better results at 12 than 6 months. Few randomized studies have been performed in asymptomatic PHPT showing no clear benefit in favor of surgery, but these studies showed a decrease of anxiety and phobia (10), an improvement of global health, mental health, and vitality (11) after surgical cure of mild pHPT $(10,11,19)$. Differences observed between surgical literature and these randomised studies may be due to the fact that patients seen by surgeons are more symptomatic than those seen by endocrinologists.

Furthermore, the subgroup analysis showed a greater improvement in symptoms at 1 year in patients $\leq 70$ years (nine vs four symptoms). Although older patients have more nonspecific symptoms than younger ones, including mood disorders, bone, and articular pains, the symptoms of fatigue, loss of appetite, headache, and polydipsia were still improved in patients $>70$ years. Previous studies showed an improvement in these symptoms and quality of life in older patients, but most of these studies used 50 years old as the cut-off (20). In addition, we demonstrated that preoperative serum calcium level $\geq 2.6 \mathrm{mmol} / \mathrm{l}$ was associated with a greater improvement at 1 year of nonspecific symptoms compared with patients with a preoperative serum calcium level $<2.6 \mathrm{mmol} / \mathrm{l}$ (11 vs two symptoms). Finally, patients under 70 years or/and with serum calcium level $\geq 2.6 \mathrm{mmol} / \mathrm{l}$ have greater symptom improvement than all others groups.
To select more accurately patients for surgery, a clinical score based on age and the most relevant nonspecific symptoms was created. Several studies have attempted to develop more specific scores of pHPT, but were not focused on mild pHPT. Pasieka et al., in a prospective study comparing pHPT patients with patients with a nontoxic thyroid nodule, used a questionnaire including 13 items. There were more symptoms in the pHPT than that in the thyroid group preoperatively $(P<0.01)(14)$. There was a significant improvement in symptoms between the preoperative and immediate postoperative period (between 7 and 10 days postoperatively). This study prospectively validated a score called Parathyroidectomy Assessment of Symptoms (PAS) score, specific to pHPT (18). This score was a scale to evaluate patients pre- and postoperatively. A multicentric study confirmed these results (15). The use of this score confirmed that patients with mild pHPT have more nonspecific symptoms than patients who underwent thyroidectomy. The improvement in the postoperative score was independent of 2008 Consensus Conference criteria (21). In this study, the PAS score was not used but a new predictive score has been developed, which incorporated some items from the PAS and other nonspecific symptoms from the literature. More recently, the first disease-specific HRQoL questionnaire for PHPT patients (PHPQoL-16) has been developed (22). As with the PAS score, it could not help to predict postoperative clinical improvement. This study allowed extracting a preoperative clinical score with relevant preoperative items: age, presence or absence of preoperative weight loss, abdominal pain, abdominal distension, fatigue, and depressive symptoms. This scoring system had a PPV of $81 \%$ for 'clinical improvement' and can be used by clinicians in consultation with patients preoperatively. Patients with a high predictive score should be advised that they have a higher probability of symptom improvement compared with patients with a score $\leq 3$. The vitamin D level did not influence the score pre- or postoperatively. This leads to consider that only surgery may explain health improvement.

There were some limitations in this study. This study did not compare surgery and medical treatment. However, other studies have shown that control of pHPT using these medications is not as effective (23). The issue of placebo effect may also play a role for these nonspecific symptom findings. This is hard to address and will remain to be a source of continued controversy. The analysis of hypophosphoremia had not been made. We do not think that the changes in phosphoremia were important enough to explain the health improvement, as the threshold for hypophosphoremia to become symptomatic is much lower (24). All patients were corrected at 3 months. Finally, a randomized study comparing surgery and medical management may be necessary to validate this improvement and the score. 


\section{Conclusion}

In conclusion, mild pHPT nonspecific symptoms improve after parathyroidectomy. Younger patients and patients with a preoperative serum calcium level $\geq 2.6 \mathrm{mmol} / \mathrm{l}$ show the most improvement. However, improvement is still shown in patients $>70$ years and with a serum calcium level $<2.6 \mathrm{mmol} / \mathrm{l}$. Also, a clinical score $>3$ has a PPV of $81 \%$ for improvement. Clinicians may incorporate this score into preoperative discussion with patients on symptom improvement postoperatively. Finally, although the predictive model has been developed, an external data set is required to validate these findings and is the goal of future projects.

\section{Declaration of interest}

The authors declare that there is no conflict of interest that could be perceived as prejudicing the impartiality of the research reported.

\section{Funding}

This research did not receive any specific grant from any funding agency in the public, commercial or not-for-profit sector.

\section{Author contribution statement}

Study concept and design: C Caillard, B Cariou, and E Mirallié. Acquisition of data: C Blanchard, M Mathonnet, F Sebag, C Caillard, A Hamy, V Wyart, D Drui, and J-F Henry. Analysis and interpretation of data: C Blanchard, D Drui, C Volteau, P Rodien, J-B Hardouin, and E Mirallié. Drafting of the manuscript: C Blanchard, M Roy, B Cariou, and $\mathrm{E}$ Mirallié. Critical revision of the manuscript for important intellectual content: B Cariou, J-F Henry, A Hamy, P Rodien, and F Archambeaud. Administrative, technical, statistical, and material support: C Volteau, J-B Hardouin, M-F Heymann, V Wyart, M Roy, and R Zarnegar. Study supervision: C Caillard and E Mirallié.

\section{Acknowledgement}

The authors thank Caroline Kubis and Elise Van Nuvel for help in collecting data.

\section{References}

1 Bilezikian JP \& Potts JT Jr. Asymptomatic primary hyperparathyroidism: new issues and new questions - bridging the past with the future. Journal of Bone and Mineral Research 200217 (Suppl 2) N57-N67.

2 Wermers RA, Khosla S, Atkinson EJ, Achenbach SJ, Oberg AL, Grant CS \& Melton LJ III. Incidence of primary hyperparathyroidism in Rochester, Minnesota, 1993-2001: an update on the changing epidemiology of the disease. Journal of Bone and Mineral Research 2006 21 171-177. (doi:10.1359/JBMR. 050910)

3 Bilezikian JP, Khan AA \& Potts JT Jr. Guidelines for the management of asymptomatic primary hyperparathyroidism: summary statement from the Third International Workshop. Journal of Clinical Endocrinology and Metabolism 200994 335-339. (doi:10.1210/jc.2008-1763)

4 Bilezikian JP, Potts JT Jr, Fuleihan GE-H, Kleerekoper M, Neer R, Peacock M, Rastad J, Silverberg SJ, Udelsman R \& Wells SA. Summary statement from a workshop on asymptomatic primary hyperparathyroidism: a perspective for the 21st century. Journal of Clinical Endocrinology and Metabolism $2002 \quad 87$ 5353-5361. (doi:10.1210/jc.2002-021370)

5 NIH conference. Diagnosis and management of asymptomatic primary hyperparathyroidism: consensus development conference statement. Annals of Internal Medicine $1991 \quad 114$ 593-597. (doi:10.7326/0003-4819-114-7-593)

6 Blanchard C, Mirallié E \& Mathonnet M. Sporadic primary hyperparathyroidism. Journal of Visceral Surgery $2010 \mathbf{1 4 7}$ e285-e295. (doi:10.1016/j.jviscsurg.2010.08.018)

7 Bollerslev J, Marcocci C, Sosa M, Nordenström J, Bouillon R \& Mosekilde L. Current evidence for recommendation of surgery, medical treatment and vitamin $\mathrm{D}$ repletion in mild primary hyperparathyroidism. European Journal of Endocrinology 2011165 851-864. (doi:10.1530/EJE-11-0589)

8 Caillard C, Sebag F, Mathonnet M, Gibelin H, Brunaud L, Loudot C, Kraimps JL, Hamy A, Bresler L, Charbonnel B et al. Prospective evaluation of quality of life (SF-36v2) and nonspecific symptoms before and after cure of primary hyperparathyroidism (1-year follow-up). Surgery 2007141 153-159. (doi:10.1016/j.surg. 2006.12.004)

9 Calzada-Nocaudie M, Chanson P, Conte-Devolx B, Delemer B, Estour B, Henry J-F, Houillier P, Kraimps JL, Ribot C, Rohmer V et al. Management of asymptomatic primary hyperparathyroidism: French Society of Endocrinology expert consensus. Annales d'Endocrinologie 200667 7-12. (doi:10.1016/S0003-4266(06) 72533-1)

10 Rao DS, Phillips ER, Divine GW \& Talpos GB. Randomized controlled clinical trial of surgery versus no surgery in patients with mild asymptomatic primary hyperparathyroidism. Journal of Clinical Endocrinology and Metabolism 200489 5415-5422. (doi:10.1210/jc.2004-0028)

11 Ambrogini E, Cetani F, Cianferotti L, Vignali E, Banti C, Viccica G, Oppo A, Miccoli P, Berti P, Bilezikian JP et al. Surgery or surveillance for mild asymptomatic primary hyperparathyroidism: a prospective, randomized clinical trial. Journal of Clinical Endocrinology and Metabolism 200792 3114-3121. (doi:10. 1210/jc.2007-0219)

12 Joborn C, Hetta J, Lind L, Rastad J, Akerström G \& Ljunghall S. Self-rated psychiatric symptoms in patients operated on because of primary hyperparathyroidism and in patients with long-standing mild hypercalcemia. Surgery 1989105 72-78.

13 Siperstein AE, Shen W, Chan AK, Duh QY \& Clark OH. Normocalcemic hyperparathyroidism. Biochemical and symptom profiles before and after surgery. Archives of Surgery 1992127 1157-1161. (doi:10.1001/archsurg.1992.01420100015003)

14 Pasieka JL \& Parsons LL. Prospective surgical outcome study of relief of symptoms following surgery in patients with primary hyperparathyroidism. World Journal of Surgery 199822 513-518. (doi:10.1007/s002689900428)

15 Pasieka JL, Parsons LL, Demeure MJ, Wilson S, Malycha P, Jones J \& Krzywda B. Patient-based surgical outcome tool demonstrating alleviation of symptoms following parathyroidectomy in patients with primary hyperparathyroidism. World Journal of Surgery 2002 26 942-949. (doi:10.1007/s00268-002-6623-y)

16 Okamoto T, Gerstein HC \& Obara T. Psychiatric symptoms, bone density and non-specific symptoms in patients with mild hypercalcemia due to primary hyperparathyroidism: a systematic overview of the literature. Endocrine Journal $1997 \mathbf{4 4} 367-374$. (doi:10.1507/endocrj.44.367)

17 Roman SA, Sosa JA, Pietrzak RH, Snyder PJ, Thomas DC, Udelsman R \& Mayes L. The effects of serum calcium and parathyroid hormone changes on psychological and cognitive function in patients undergoing parathyroidectomy for primary hyperparathyroidism. Annals of Surgery 2011253 131-137. (doi:10.1097/SLA.0b013e3181f66720)

18 Weber T, Eberle J, Messelhäuser U, Schiffmann L, Nies C, Schabram J, Zielke A, Holzer K, Rottler E, Henne-Bruns D et al. Parathyroidectomy, elevated depression scores, and suicidal 
ideation in patients with primary hyperparathyroidism: results of a prospective multicenter study. Journal of the American Medical Association 2013148 109-115.

19 Bollerslev J, Jansson S, Mollerup CL, Nordenström J, Lundgren E, Torring O, Varhaug JE, Baranowski M, Aanderud S, Franco C et al. Medical observation, compared with parathyroidectomy, for asymptomatic primary hyperparathyroidism: a prospective, randomized trial. Journal of Clinical Endocrinology and Metabolism 200792 1687-1692. (doi:10.1210/jc.2006-1836)

20 Roche NA \& Young AE. Role of surgery in mild primary hyperparathyroidism in the elderly. British Journal of Surgery 200087 1640-1649. (doi:10.1046/j.1365-2168.2000.01 628.x)

21 Sywak MS, Knowlton ST, Pasieka JL, Parsons LL \& Jones J. Do the National Institutes of Health consensus guidelines for parathyroidectomy predict symptom severity and surgical outcome in patients with primary hyperparathyroidism? Surgery 2002132 1013-1019. (doi:10.1067/msy.2002.128693)
22 Webb SM, Puig-Domingo M, Villabona C, Muñoz-Torres M, Farrerons J \& Badia X. Development of a new tool for assessing Health-Related Quality of Life in patients with primary hyperparathyroidism. Health and Quality of Life Outcomes 20131197. (doi:10.1186/1477-7525-11-97)

23 Keutgen XM, Buitrago D, Filicori F, Kundel A, Elemento O, Fahney TJ \& Zarnegar R. Calcimimetics versus parathyroidectomy for treatment of primary hyperparathyroidism: retrospective chart analysis of a prospective database. Annals of Surgery 2012255 981-985. (doi:10.1097/SLA.0b013e31824c5252)

24 Gaasbeek A \& Meinders A. Hypophosphatemia: an update on its etiology and treatment. American Journal of Medicine 2005118 1094-1101. (doi:10.1016/j.amjmed.2005.02.014)

Received 20 June 2013

Revised version received 3 August 2013

Accepted 16 August 2013 